\title{
SUBSTANTIATION OF COMPONENTS OF AVAILABILITY AND INTEGRATION OF PRIMARY HEALTH CARE ASSOCIATED WITH AMBULATORY CARE SENSITIVE CONDITIONS IN UKRAINE
}

DOI: $10.36740 /$ WLek202103204

\author{
Valery N. Lekhan, Liudmyla 0. Hrytsenko \\ DNIPROPETROVSK MEDICAL ACADEMY OF HEALTH MINISTRY OF UKRAINE, DNIPRO, UKRAINE
}

\begin{abstract}
The aim: Identifying the components of availability of Primary Health Care (PHC) and integration between PHC and secondary Health care (SHC) which need strengthening to reduce the rate of Ambulatory Care Sensitive Hospitalizations (ACSH) in Ukraine.

Materials and methods: The study was conducted in two stages: the focus of interviewing experts on the list of components of the availability of PHC and its integration with SHC; survey of our questionnaire is based on the results of the first stage of the study. The responses of 93 respondents -20 experts and 73 general practitioners/family doctors - were analyzed using descriptive and analytical statistics.

Results: There were identified 14 components of PHC availability and 8 integration components of PHC with SHC, their quantitative value (in points) of impact on ACSH. The informativeness of components is confirmed by the agreement of opinions of experts on their list (concordance coefficient $W=0.75-0.87 ; p<0.01$ ) and the reliable correlations of scores of impact assessments of the identified components with overall values of the impact availability PHC and the integration between PHC and SHC on the ACSH.

Conclusions: The results of the study can be used to develop an action plan for reform of PHC, the implementation of which will reduce rates hospitalizations of Ambulatory care sensitive conditions and increase the efficiency use of limited resources of health care system of Ukraine.
\end{abstract}

KEY WORDS: Ambulatory care sensitive conditions, Ambulatory Care Sensitive Hospitalizations, Primary Health Care, Ukraine

$\overline{\text { Wiad Lek. 2021;74(3 p.II):584-588 }}$

\section{INTRODUCTION}

At the present stage of development of health care systems, it is considered proven that strengthening primary health care (PHC) allows not only to have a positive impact on public health but also to reduce overall health care costs and increase its efficiency by reducing the number of hospitalizations [1].

An important direction in the development of policies to prevent hospitalization is the impact on ambulatory care sensitive conditions (ACSCs). According to the WHO, these are "conditions for which hospitalizations can be avoided by timely and effective care in ambulatory settings» [2], first of all, at the level of PHC.

Studies conducted in different countries indicate the possibility of some control over the hospitalization of patients with ACSC. Thus, in Canada for the period from 2006-2007 to 2011-2012, the level of hospitalization of the population aged 0-74 years from ACSCs decreased from $8.96 \%$ to $6.33 \%$ [3], in Brazil from 2001 to 2016. - from $12.0 \%$ o to $6.6 \%$ [ [4].

The results of our previous studies show that in Ukraine, with the strengthening of $\mathrm{PHC}$, it is possible to reduce the rate of Ambulatory Care Sensitive Hospitalizations (ACSH) for adult population by $28.2 \%--32.9 \%$ [5].

However, the evidence for the effectiveness of interventions that reduce hospitalizations for ACSCs is rather limited. Among the medical predictors of reduced hospitalizations for ACSH in international studies, the availability of PHC and the integration of primary and secondary care levels are highlighted [6]. In Ukraine, research on the components of the impact on these characteristics of medical services has not been conducted, which caused the relevance of this work.

\section{THE AIM}

The aim of the study is to identify the main components of the availability of Primary Health Care (PHC) and the integration between primary and secondary care levels which need to be strengthened to reduce the rates of Ambulatory Care Sensitive Hospitalizations or ACSH in Ukraine.

\section{MATERIALS AND METHODS}

There are two stages in the study. The first stage was to determine a set of main components of the availability of primary health care (PHC) and the integration of primary and ambulatory specialized - secondary health care (SHC) related to ambulatory care sensitive conditions (ACSCs); the second one - to assess the potential impact of identified components on the prevention of ACSHs. The list of main components (Stage 1) was developed using 


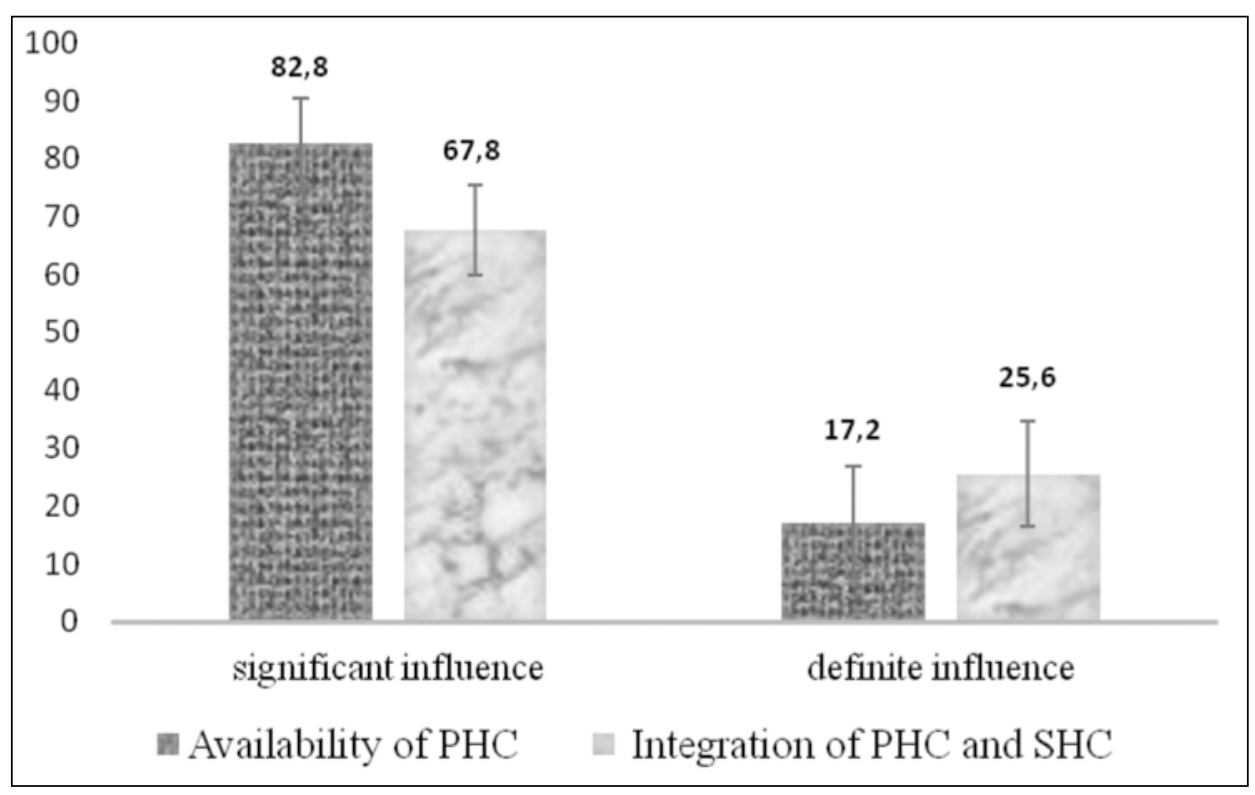

Fig. 1. Respondents' assessment of the significance of the impact of PHC availability and integration between primary and secondary care levels on prevention of ambulatory care sensitive hospitalizatios (ACSH) the focused interview method. First of all, based on the analysis of literature sources [7], we developed a list of 21 components to characterize the availability of PHC and 14 components - to assess the coordination between primary and secondary care levels. Further, there were some interviews conducted in 2 distance focus groups formed from the number of general practitioners/family doctors (GP/FD)and PHC managers, numbering 10 people each. The focus group participants were members of the board of the Ukrainian Family Medicine Association.

Inclusion in the focus groups took place after testing the competence of potential respondents for ACSCs according to the method of B.E. Grabovetsky [8]. Only respondents who received a threshold score of at least 0.8 were confirmed as those who demonstrated high compliance survey requirements and continued to be referred to in this study as experts. The interviews were conducted in several rounds until the experts agreed.

Materials for the second stage of the analysis were obtained from the responses to the survey based on our questionnaire, which proposed to assess on a 10-point scale the potential impact of selected components on prevention of ACSH. The survey was conducted among the most active members of the association of family doctors of Dnipropetrovsk region (73 answers from 90 doctors, $84 \%$ of the response) and 20 experts identified in the first stage of the study. A total of 93 people took part in the survey..

Involved physicians had an average work experience of 10 (Me 7.0; 25.0) years, $54.8 \%$ of those who work in the urban area, $45.2 \%$ - in rural settlements; experts had an average work experience of $15.0(7.0 ; 25.0)$ years, $100 \%$ of respondents worked in urban settlements. There were no differences between the selected groups by work experience ( $p>0.05$ ), but at their place of work, there were statistically significant differences $(p=0.001)$. It was taken into account in the subsequent analysis of the results.

Statistical processing of data was performed with STATISTICA 6.1 (StatSoft Inc, serial number AGAR909E415822FA).
To describe the normal distribution of the sample data we used the arithmetic mean $(\mathrm{M})$ with a 95\% confidence interval (95\% CI); for asymmetric distribution we used median (Me) with interquartile range (25\%; $75 \%$ ). For relative values, $95 \%$ CI was calculated using adjusted Wald method. Methods of statistical analysis included estimating the statistical significance discrepancies by Mann-Whitney test for unrelated samples; Wilcoxon test for related samples, and by Pearson's Chi-square $(\chi 2)$ test. For multiple comparisons of variables, we used a nonparametric Kruskal-Wallis analysis of variance.

The relationships between the variables were evaluated using rank correlation analysis with Spearman correlation coefficients $\left(r_{s}\right)$. The concordance coefficient $(\mathrm{W})$ was used as statistics of agreement of opinions. The critical value of statistical significance for all types of analysis was taken at the level of $\mathrm{p}<0.05$.

The study has a positive response on the use of research methods from the commission on bioethics (minutes of the meeting of the commission on biomedical ethics of the SI Dnipropetrovsk Medical Academy of Health Ministry of Ukraine №8 from 20.01.2021.

\section{RESULTS}

According to the total number of responds, both characteristics - the availability of primary care (PHC) and their integration between primary and secondary care levels can significantly affect the prevention of ACSH (figure 1), however, the share of respondents who assessed the impact of PHC availability as significant was significantly higher $(p=0.02)$ than those who in such a way assessed the integration of PHC and SHC (82.8\%). (CI 95\%. 75.0; 90.0)) and $(67.7 \%$ (CI 95\%. 58.0; 77.0) respectively)).

After two rounds of interviews, both groups of experts agreed on a list of $14 \mathrm{PHC}$ accessibility components and 8 integration components between $\mathrm{PHC}$ and SHC (concordance coefficients $\mathrm{W}=0.87$ and $\mathrm{W}=0.75 ; \mathrm{p}<0.01$ respectively). The list of components for both characteristics and the values on a 10-point scale of their potential impact on 
Table I. Assessment of the potential impact of PHC availability components by a 10-point scale (10 - maximum effect, 0 - no effect) on prevention of ACSH in points: (Me (25\%; 75\%))

\begin{tabular}{|c|c|c|c|c|c|}
\hline \multicolumn{2}{|l|}{ Components of availability } & \multirow{2}{*}{$\begin{array}{c}\text { Experts } \\
n=20\end{array}$} & \multirow{2}{*}{$\begin{array}{l}\text { GP/FD } \\
n=73\end{array}$} & \multirow{2}{*}{$\begin{array}{l}\text { Total } \\
\mathrm{n}=93\end{array}$} & \multirow{2}{*}{$\begin{array}{c}p \\
\text { between } \\
\text { groups }\end{array}$} \\
\hline Title & Code & & & & \\
\hline Nearness of point of PHC care to community & $C_{1} a$ & $\begin{array}{c}10.0 \\
(8.5 ; 10)\end{array}$ & $\begin{array}{c}9.0 \\
(8.0 ; 10.0)\end{array}$ & $\begin{array}{c}9.0 \\
(8.0 ; 10.0)\end{array}$ & 0.37 \\
\hline Staffing of PHC facilities with GP/FD & $\mathrm{C} 2 \mathrm{a}$ & $\begin{array}{c}9.0 \\
(8.0 ; 10.0)\end{array}$ & $\begin{array}{c}8.0 \\
(8.0 ; 10.0)\end{array}$ & $\begin{array}{c}8.0 \\
(8.0 ; 10.0)\end{array}$ & 0.33 \\
\hline Staffing of PHC facilities with nurses & $\mathrm{C} 3 \mathrm{a}$ & $\begin{array}{c}9.5 \\
(8.5 ; 10.0)\end{array}$ & $\begin{array}{c}10.0 \\
(9.0 ; 10.0)\end{array}$ & $\begin{array}{c}10.0 \\
(9.0 ; 10.0)\end{array}$ & 0.55 \\
\hline $\begin{array}{l}\text { Compliance with the requirements } \\
\text { of the equipment of the } \mathrm{PHC} \text { facility }\end{array}$ & $\mathrm{C} 4 \mathrm{a}$ & $\begin{array}{c}9.0 \\
(8.0 ; 10.0)\end{array}$ & $\begin{array}{c}10.0 \\
(8.0 ; 10.0)\end{array}$ & $\begin{array}{c}10.0 \\
(8.0 ; 10.0)\end{array}$ & 0.66 \\
\hline $\begin{array}{l}\text { Normative regulation of ranking ACSC } \\
\text { to prioritized }\end{array}$ & $\mathrm{C} 5 \mathrm{a}$ & $\begin{array}{c}9.0 \\
(8.0 ; 9.5)\end{array}$ & $\begin{array}{c}10.0 \\
(8.0 ; 10.0)\end{array}$ & $\begin{array}{c}9.0 \\
(8.0 ; 10.0)\end{array}$ & 0.17 \\
\hline $\begin{array}{c}\text { Sufficient level of professional competence } \\
\text { of PHC physician }\end{array}$ & $\mathrm{C6a}$ & $\begin{array}{c}9.0 \\
(8.0 ; 10.0)\end{array}$ & $\begin{array}{c}9.0 \\
(7.0 ; 10.0)\end{array}$ & $\begin{array}{c}9.0 \\
(7.0 ; 10.0)\end{array}$ & 0.59 \\
\hline $\begin{array}{c}\text { Sufficient level of professional competence } \\
\text { of nurses }\end{array}$ & $\mathrm{C} 7 \mathrm{a}$ & $\begin{array}{c}10.0 \\
(9.0 ; 10.0)\end{array}$ & $\begin{array}{c}10.0 \\
(9.0 ; 10.0)\end{array}$ & $\begin{array}{c}10.0 \\
(9.0 ; 10.0)\end{array}$ & 0.63 \\
\hline $\begin{array}{l}\text { Convenience for patients of fixing an appointment } \\
\text { to PHC physician }\end{array}$ & $\mathrm{C} 8 \mathrm{a}$ & $\begin{array}{c}10.0 \\
(9.0 ; 10.0)\end{array}$ & $\begin{array}{c}10.0 \\
(9.0 ; 10.0)\end{array}$ & $\begin{array}{c}10.0 \\
(9.0 ; 10.0)\end{array}$ & 0.77 \\
\hline Convenience for patients of doctors' work schedule & $C 9^{a}$ & $\begin{array}{c}9.0 \\
(8.0 ; 9.0) \\
\end{array}$ & $\begin{array}{c}9.0 \\
(8.0 ; 10.0) \\
\end{array}$ & $\begin{array}{c}9.0 \\
(8.0 ; 10.0) \\
\end{array}$ & 0.39 \\
\hline Availability of timely emergency medical care & $\mathrm{C} 10 \mathrm{a}$ & $\begin{array}{c}9.0 \\
(8.0 ; 9.0)\end{array}$ & $\begin{array}{c}10.0 \\
(8.0 ; 10.0)\end{array}$ & $\begin{array}{c}9.0 \\
(8.0 ; 10.0)\end{array}$ & 0.67 \\
\hline Availability of medical care to the patient at home & C11a & $\begin{array}{c}10.0 \\
(8.5 ; 10.0) \\
\end{array}$ & $\begin{array}{c}10.0 \\
(8.0 ; 10.0) \\
\end{array}$ & $10.0(8.0 ; 10.0)$ & 0.23 \\
\hline $\begin{array}{l}\text { The possibility of conducting evidence-based } \\
\text { screening studies for detection of ACSC }\end{array}$ & $\mathrm{C} 12 \mathrm{a}$ & $\begin{array}{c}9.0 \\
(8.0 ; 9.5)\end{array}$ & $\begin{array}{c}9.0 \\
(8.0 ; 10.0) \\
\end{array}$ & $\begin{array}{c}9.0 \\
(8.0 ; 10.0)\end{array}$ & 0.41 \\
\hline $\begin{array}{c}\text { Availability of active supervision and controlled } \\
\text { treatment of ACSC }\end{array}$ & C13a & $\begin{array}{c}9.0 \\
(9.0 ; 10.0)\end{array}$ & $\begin{array}{c}10.0 \\
(8.0 ; 10.0)\end{array}$ & $\begin{array}{c}9.0 \\
(8.0 ; 10.0)\end{array}$ & 0.16 \\
\hline $\begin{array}{l}\text { Possibility to provide patients with ACSC with } \\
\text { affordable medicines }\end{array}$ & $\mathrm{C} 14 \mathrm{a}$ & $\begin{array}{c}9.5 \\
(8.5 ; 10.0)\end{array}$ & $\begin{array}{c}9.0 \\
(8.0 ; 10.0)\end{array}$ & $\begin{array}{c}9.0 \\
(8.0 ; 10.0)\end{array}$ & 0.87 \\
\hline Availability of PHC on the whole & $\mathrm{Ca}$ & $\begin{array}{c}9.0 \\
(8.0 ; 10.0)\end{array}$ & $\begin{array}{c}9.0 \\
(8.0 ; 10.0)\end{array}$ & $\begin{array}{c}9.0 \\
(8.0 ; 10.0)\end{array}$ & 0.22 \\
\hline
\end{tabular}

Note: $\quad p$-differences between estimates of experts and primary care physicians by Mann-Whitney criteria

prevention of ACSH according to GP/FDs, experts and in general are presented in Table I and Table II.

As no significant differences according to the Mann-Whitney criteria between the groups of respondents on any of the components were found, further analysis was performed for the total number of respondents (93 people).

With the help of rank correlation analysis, a significant weak or medium-strength relationship between the scores of the impact of all components of PHC availability (except for the technical possibility to undergo instrumental examinations prescribed by a family doctor or a doctor of SHC) with its general characteristics: $r_{s}=0.23 \div 0,43 ; p<0.01$ ). The presence of an association between the place of work of the respondents (urban or rural area) and assessments of individual components of accessibility regarding the prevention of ACSH was determined: according to the staffing of PHC facilities by nurses $\left(r_{s}=0.43 ; p=0.008\right)$; compliance with the requirements of the equipment of the PHC facility $-\left(\mathrm{r}_{\mathrm{s}}=\right.$
$0.51 ; \mathrm{p}=0.008$ ); the possibility of conducting evidence-based screening studies for the timely detection of ACSCs $\left(\mathrm{r}_{\mathrm{s}}=\right.$ $0,25 ; p=0,008)$; the possibility of providing patients with ACSCs with medicines (free of charge or with an acceptable level of co-payment) $\left(\mathrm{r}_{\mathrm{s}}=0.21 ; \mathrm{p}=0.001\right)$.

Regarding the coordination of PHC and SHC, significant correlations were found between the scores of all, without exception, the components of the impact of the integration of primary and secondary care with the overall assessment of its impact on the prevention of ACSH (figure 2). Besides, the connection of the territorial convenience of the location of SHC facilities with the place of work of the respondents was determined $\left(r_{s}=0.25 ; \mathrm{p}=0.007\right)$.

\section{DISCUSSION}

The study identified a set of 14 PHC accessibility components and 8 PHC and SHC integration components, the strength- 
Table II. Assessment of the impact of PHC with SHC integration components by a 10-point scale (10 - maximum effect, 0 - no effect) on prevention of ACSH in points: (Me $(25 \% ; 75 \%))$

\begin{tabular}{|c|c|c|c|c|c|}
\hline \multicolumn{2}{|l|}{ Integration components } & \multirow{2}{*}{$\begin{array}{l}\text { Experts } \\
n=20\end{array}$} & \multirow{2}{*}{$\begin{array}{l}\text { GP/FD } \\
n=73\end{array}$} & \multirow{2}{*}{$\begin{array}{l}\text { Total } \\
\mathrm{n}=93\end{array}$} & \multirow{2}{*}{$\begin{array}{c}p \\
\text { between } \\
\text { groups }\end{array}$} \\
\hline Title & Code & & & & \\
\hline Territorial convenience of location SHC facilities & $\mathrm{C} 1 \mathrm{i}$ & $\begin{array}{c}8.0 \\
(7.0 ; 9.0)\end{array}$ & $\begin{array}{c}10.0 \\
(8.0 ; 10.0)\end{array}$ & $\begin{array}{c}9.0 \\
(8.0 ; 10.0)\end{array}$ & 0.57 \\
\hline $\begin{array}{l}\text { Possibility to give the patient a consultation with a } \\
\text { specialist in the presence of a referral from a GP/FD }\end{array}$ & $\mathrm{C} 2 \mathrm{i}$ & $\begin{array}{c}9.0 \\
(8.0 ; 9.0) \\
\end{array}$ & $\begin{array}{c}9.0 \\
(8.0 ; 10.0) \\
\end{array}$ & $\begin{array}{c}9.0 \\
(8.0 ; 10.0) \\
\end{array}$ & 0.49 \\
\hline $\begin{array}{l}\text { Possibility to give the patient a consultation with a } \\
\text { specialist in the absence of a referral from a GP/FD }\end{array}$ & $\mathrm{C} 3 \mathrm{i}$ & $\begin{array}{c}8.0 \\
(5.0 ; 9.0)\end{array}$ & $\begin{array}{c}8.0 \\
(5.5 ; 10.0)\end{array}$ & $\begin{array}{c}8.0 \\
(5.0 ; 10.0)\end{array}$ & 0.20 \\
\hline $\begin{array}{c}\text { Possibility to undergo laboratory examinations } \\
\text { appointed by a GP/FD at the minimum expenses of } \\
\text { time of the patient }\end{array}$ & C4i & $\begin{array}{c}9.0 \\
(9.0 ; 10.0)\end{array}$ & $\begin{array}{c}9.0 \\
(8.0 ; 10.0)\end{array}$ & $\begin{array}{c}9.0 \\
(8.0 ; 10.0)\end{array}$ & 0.36 \\
\hline $\begin{array}{l}\text { Availability of laboratory tests prescribed by the GP/FD } \\
\text { at minimal cost to the patient }\end{array}$ & C5 i & $\begin{array}{c}9.00 \\
(8.5 ; 10.0) \\
\end{array}$ & $\begin{array}{c}9.0 \\
(7.0 ; 10.0) \\
\end{array}$ & $\begin{array}{c}9.0 \\
(8.0 ; 10.0) \\
\end{array}$ & 0.28 \\
\hline $\begin{array}{l}\text { Technical ability to undergo instrumental } \\
\text { examinations prescribed by the GP/FD }\end{array}$ & C6i & $\begin{array}{c}9.0 \\
(8.5 ; 10.0) \\
\end{array}$ & $\begin{array}{c}9.0 \\
(7.0 ; 10.0) \\
\end{array}$ & $\begin{array}{c}9.0 \\
(8.0 ; 10.0)\end{array}$ & 0.49 \\
\hline Continuity between $\mathrm{PHC}$ and ambulatory $\mathrm{SHC}$ & C7i & $\begin{array}{c}9.0 \\
(8.5 ; 10.0) \\
\end{array}$ & $\begin{array}{c}9.0 \\
(8.0 ; 10.0) \\
\end{array}$ & $\begin{array}{c}9.0 \\
(8.0 ; 10.0) \\
\end{array}$ & 0.60 \\
\hline $\begin{array}{l}\text { Exchange of medical information between } \mathrm{PHC} \text { and } \\
\qquad \text { SHC facilities }\end{array}$ & $\mathrm{C} 8 \mathrm{i}$ & $\begin{array}{c}10.0 \\
(9.0 ; 10.0)\end{array}$ & $\begin{array}{c}9.0 \\
(6.0 ; 10.0)\end{array}$ & $\begin{array}{c}9.0 \\
(7.0 ; 10.0)\end{array}$ & 0.09 \\
\hline Integration between $\mathrm{PHC}$ and SHC on the whole & $\mathrm{C9i}$ & $\begin{array}{c}8.5 \\
(7.5 ; 10.0)\end{array}$ & $\begin{array}{c}9.0 \\
(8.0 ; 10.0)\end{array}$ & $\begin{array}{c}9.0 \\
(8.0 ; 10.0)\end{array}$ & 0.56 \\
\hline
\end{tabular}

Note: $\quad p$ - differences between estimates of experts and primary care physicians by Mann-Whitney criteria

ening of which could potentially reduce the rates of ACSHin Ukraine, which corresponds to the authors' opinion on the need for identification and specification of factors associated with the possibility of ACSH prevention [9].

The informativeness of the identified components is confirmed by the high final agreement of opinions of experts

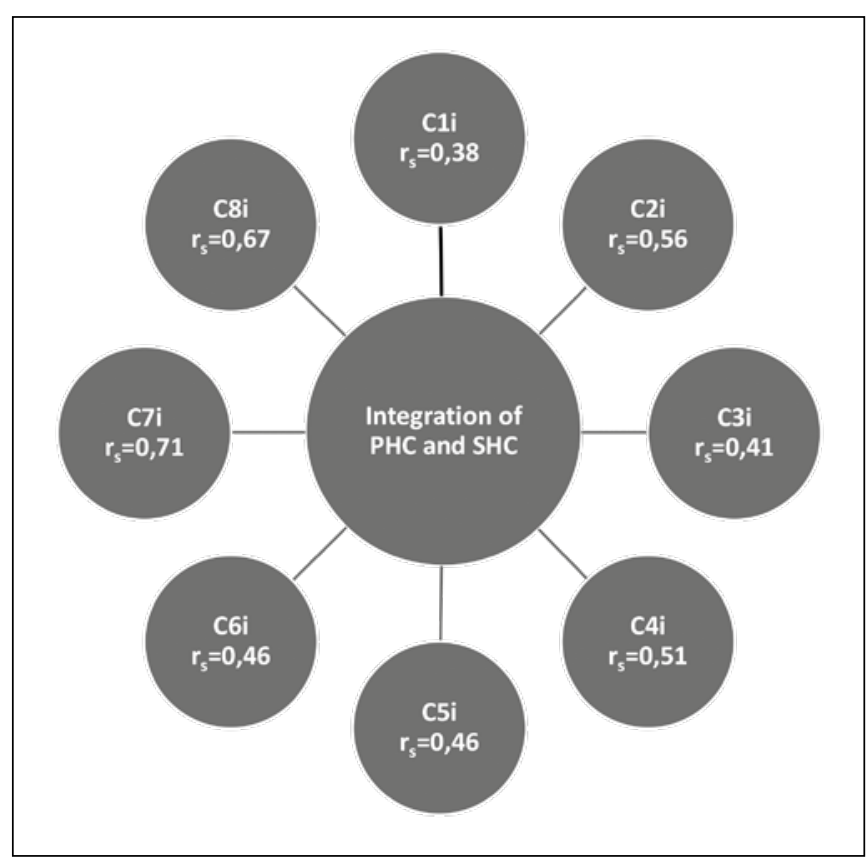

Fig. 2. Correlations between the components of the impact of $\mathrm{PHC}$ and $\mathrm{SHC}$ integration and the overall impact of integration on prevention of ACSH on their list and the presence of statistical validity of the correlations of scores of impact all identified components, except one, with the overall values of the impact of PHC availability and integration between $\mathrm{PHC}$ and SHC on prevention of ACSH.

The study also proved that certain components are more important for rural areas, in particular the staffing of PHC facilities with nurses; their compliance with the requirements for the equipment of the facility; availability of opportunities for effective screening studies to identify ACSCs and provide patients with ACSCs with affordable medicines, territorial convenience of the location of SHC facilities. Such results are explained by the territorial features of the development of the PHC system in Ukraine, which are weaker in rural areas and have fewer opportunities for integration with secondary health care [5].

To strengthen the PHC system to reduce the rates of $\mathrm{ACSH}$, respondents were proposed a set of organizational and economic measures. The most popular among them are: a) increasing the availability of PHC by ensuring the staffing of PHC facilities with doctors (76.7\% of respondents; 95\% CI 69.1 - 85.0) and improving their professional level (72.6\%; $95 \%$ CI 64.3 - 81.2); scientific substantiation of workload standards for primary care physicians $(69.9 \%$; $95 \%$ CI 61.0 - 78.8), the formation of an adequate network of PHC facilities is differentially for urban and rural areas. (67.1\%; 95\% CI 58,2 - 76.1); b) improving the integration of PHC and SHC through the development of effective forms of cooperation between primary and secondary care facilities and physicians ( 72.6\%; 95\% CI 64.3 - 81.2), cre- 
ation and implementation of end-to-end clinical protocols (68.5\%; 95\% CI 60.0 - 76.8).

In general, focusing on transformations on certain components of PHC availability and its integration with SHC that have a potential impact on the prevention of ACSH can significantly increase the effectiveness of primary health care and health care on the whole.

Our study has several limitations, including the following:

1. As our study is mainly based on the survey a significant number of respondents (primary care physicians) from one region of Ukraine, our analysis may have an ecological error.

2. A problem for the practical application of data on the components of accessibility of PHC and its integration with SHC that have a potential impact on the prevention of Ambulatory Care Sensitive Hospitalizations may be the need to raise additional funds for the implementation of structural changes, retraining and motivation of medical staff both in primary and ambulatory secondary health care sector.

Prospects for further research are to conduct an organizational experiment on a pilot site to determine the real impact of PHC availability components and its integration with SHC on prevention of ACSH.

\section{CONCLUSIONS}

The study lists and assesses the impact of the main components of primary care availability and its integration with secondary care associated with ambulatory care sensitive conditions that can be used for potentially preventable hospitalizations. The study showed the directions of prioritization of measures aimed at strengthening the primary health care system in Ukraine. The results of the study can be used to develop a specific action plan for further reform of primary health care, the implementation of which will reduce rates of ambulatory care sensitive hospitalizations and increase the efficient use of limited resources within a health care system of Ukraine

\section{REFERENCES}

1. Report of the Global Conference on Primary Health Care: From Alma-Ata towards Universal Health Coverage and the Sustainable Development Goals / World Health Organization. Geneva: WH0. 2019: 74.

2. Assessing health services delivery performance with hospitalizations for ambulatory care sensitive conditions. World Health Organization. WHO Regional Office for Europe: Copenhagen. 2016: 43.

3. Fransoo R. Hospitalization Rates for Ambulatory Care Sensitive (ACS) Conditions. In: Fransoo R., Martens P., Prior H. et al. The 2013 RHA Indicators Atlas. Winnipeg, MB: Manitoba Centre for Health Policy. 2013:203-206.

4. Pinto L.F., Giovanella L. The Family Health Strategy: expanding access and reducing hospitalizations due to ambulatory care sensitive conditions (ACSC). Cien Saude Colet. 2018; 23(6):1903-1914. doi: 10.1590/1413-81232018236.05592018.
5. Lekhan V.N., Kriachkova L.V., Doroshenko 0.0., Gritsenko L.0. Estimates of potentially preventable hospitalizations for ambulatory care sensitive conditions in Ukraine. Medicni perspektivi. 2020;25(4):189-198. doi: https://doi.org/10.26641/2307-0404.2020.4.221711.

6. Santana R., Santos R.F., Sarmento J. et al. Determinants of ambulatory care sensitive conditions hospitalizations - the patients' perspective. International Journal of Integrated Care. 2018;18(s2):376. http://doi. org/10.5334/ijic.s2376.

7. Nadutyi K.O., Lekhan V.M., Tolstanov 0.K. Metodychni pidkhody do standartyzatsii otsinky diialnosti zakladiv pervynnoi medychnoi dopomohy [Methodical approaches to standardization of assessment of primary health care facilities]. Ukrainskyi medychnyi chasopys. 2019; 3(2):131. doi 10.32471/umj.1680-3051.131.157991. (In Ukrainian).

8. Hrabovetskyi B.Ye. Metody ekspertnykh otsinok: teoriia, metodolohiia, napriamky vykorystannia: monohrafiiai. [Methods of expert assessments: theory, methodology, areas of use: mogography]. Vinnytsia : VNTU. 2010: 171. (In Ukrainian).

9. Longman J.M., Passey M.E., Ewald D.P. et al. Admissions for chronic ambulatory care sensitive conditions - a useful measure of potentially preventable admission? BMC Health Serv Res. 2015;15:472. https://doi. org/10.1186/s12913-015-1137-0.

The study was performed within the research of the Department of Social medicine, public health and health management: "Scientific substantiation of organizational and methodological foundations of the system of continuous improvement of the quality of medical care" (2020-2023, № state registration 0119U101403).

\section{ORCID and contributionship:}

Valery N. Lekhan: 0000-0003-2953-3292 A, B, C, D, E, F

Liudmla O. Hrytsenko: 0000-0003-2088-538X ${ }^{B, C, D}$

\section{Conflict of interest:}

The Authors declare no conflict of interest.

\author{
CORRESPONDING AUTHOR \\ Valery N. Lekhan \\ Dnipropetrovsk Medical Academy of Health Ministry of Ukraine \\ 9 V.Vernadsky str., 49044 Dnipro, Ukraine \\ tel: +380677137118 \\ e-mail:v.n.lexan@gmail.com
}

Received: 05.10 .2020

Accepted: 03.03.2021
A - Work concept and design, B - Data collection and analysis, C - Responsibility for statistical analysis, D-Writing the article, $\mathbf{E}$-Critical review, $\mathbf{F}$ - Final approval of the article 